\title{
Influence of neonatal treatment on maternal behavior: A confounding variable'
}

RICHARD D. YOUNG

INDIANA UNIVERSITY

\begin{abstract}
Postparturitional rats when given a choice of either an experimentally treated (hypothermia and rotated) or a control neonate, significantly preferred the control. Experimental treatment of one half the litter disrupted maternal retrieving scores for all offspring. The results suggest that early experience studies may have a serious confounding variable.
\end{abstract}

\section{Problem}

Most of the experimental literature related to the effects of early (pre-weaning) experience, such as handling, shock, hypothermia, has implicitly (Denenberg, 1962) or explicitly (Levine, 1962) assumed the primary behavioral changes are due to physiological changes in the neonate which are a direct result of the treatment variable. Recently Rosenblatt \& Lehrman (1963), using a 5- to 10-day-old stimulus neonate, have reported that maintenance of normal postparturitional maternal responses depends in part upon stimulation from the litter. Many of the treatment techniques utilized in the early experience studies undoubtedly change the stimulus properties of the neonate. This suggests that treatment of the neonate may have an effect upon the maternal behavior, thus changing maternal-offspring behavior interaction and perhaps the later behavior of the treated offspring.

The present experiment was designed specifically to determine whether two neonatal treatment techniques, which had previously been reported effective in changing later behavior, would be effective in changing maternal behavior at the time of treatment.

\section{Method}

Latency to retrieve and choice of neonate retrieved were the two measures recorded. The test equipment consisted of an open field 20 in by 20 in by 10 in painted gray. One corner of the field was cut out so that the maternal home cage could open into the field. In the opposite corner from the home cage door, two 3 in circles 4 in apart were painted. The neonates were placed in these circles. Latency was recorded from leaving the home cage until the $\mathrm{S}$ re-entered the cage with an offspring.

During the first three days after parturition, each maternal $\mathrm{S}$ was allowed to explore the open-field $10 \mathrm{~min}$./day but her litter was not disturbed. All litters were maintained at a size of eight neonates. On days 4-6, the offspring were removed from the litter and were placed in the open-field two at a time. Latency was recorded for each trial. Only mothers who retrieved on all trials on days 5-6 were used in the study。
Litters were assigned to one of three treatment conditions. Under each treatment condition one half the neonates in a litter remained in the cage while the remainder received the assigned treatment. The three treatment conditions were: (1) hypothermianeonates were placed in a refrigerator at approximately $7^{\mathrm{O}} \mathrm{C}$ for $30 \mathrm{~min}$; (2) mechanical rotation-neonates were rotated $10 \mathrm{rpm}$ for $10 \mathrm{~min}$. in a closed plastic cylinder; (3) control-Ss remained with their mothers until just before testing. Days 7-9 were used as test days.

In the first series of retrieval tests (DC), two neonates (one treated and one non-treated) from the mother's own litter were placed in the circles. A trial consisted of retrieving one of the two neonates. The remaining neonate was removed and two new neonates were placed in the circles. Each maternal $S$ received four trials/ day.

In a second series of tests (SC), with a new group of maternal $\mathrm{Ss}$, neonates were placed in the field one at a time in a random order of treated vs. non-treated. In both series, a random order determined the circle in which the treated neonate was placed.

Four Ss who were given hypothermia neonates and one $\mathrm{S}$ given rotated offspring refused to retrieve any offspring on the first day (7th day) of retrieval testing. Additional maternal Ss were run so that a total of 15 Ss were used in each of the retrieve studies. Results

There were no significant differences between groups on the last day of retrieval training. In the statistical analyses of the latency scores the maternal Ss' mean score/day was utilized. The mean of the maternal mean latency scores for the three test days showed very marked increases when one half the neonates were given one of the two treatments. Maternal Ss given a two-choice retrieval test continued to reveal the increased latency over the next three days; however, Ss given a single choice returned to approximately the base level retrieving time (see Fig。1)。

An analysis of variance for repeated measures indicated significant differences between Treatment Conditions $(\mathrm{DC}-\mathrm{F}=24.04 ; \mathrm{df}=2 / 12 ; \mathrm{p}<.01 ;$ and $\mathrm{SC}-\mathrm{F}=$ 13.61; $\mathrm{df}=2 / 12$; and between Trials (DC $-\mathrm{F}=40.81$; $\mathrm{df}=2 / 24 ; \mathrm{p}<.01 ;$ and $\mathrm{SC}-\mathrm{F}=21.35 ; \mathrm{df}=2 / 24 ; \mathrm{p}<.01$ ) and a significant Treatment by Trials interaction $(\mathrm{DC}-\mathrm{F}=5.77 ; \mathrm{df}=4 / 24 ; \mathrm{p}<.01$ and $\mathrm{SC}-\mathrm{F}=9.3 ; \mathrm{df}=4 / 24$; $\mathrm{p}<.01)$. Both the Hypothermia and Rotation Groups were significantly different $(p<.05)$ from the Control Group but were not significantly different from one 


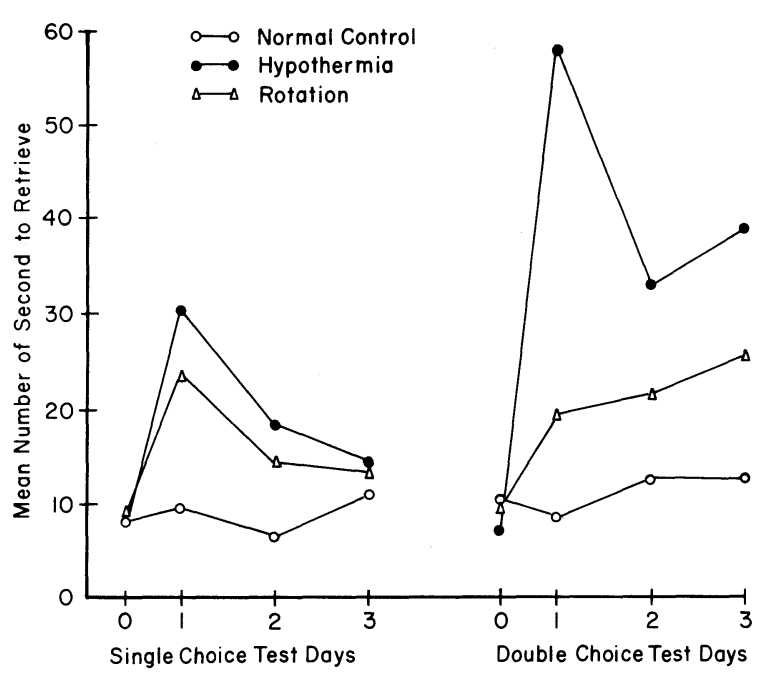

Fig. 1.

another under the SC condition. All three groups were significantly different $(p<.01)$ from one another under the DC condition.

A binomial test applied to the choice of retrieved neonate from the DC condition revealed that within a litter, the $\mathrm{S}$ preferred non-treated (total $\mathrm{N}$ chosen = $48)$ to Hypothermia $(\mathrm{N}=12)$ offspring $(\mathrm{p}<.01)$ and non-treated $(\mathrm{N}=44)$ to Rotation $(\mathrm{N}=16)$ offspring $(p<.05)$. Within a treatment condition the latency scores for treated vs. non-treated neonates were not significantly different, however, there was a marked and consistent trend toward higher latencies when a treated neonate was retrieved.

\section{Discussion}

Postparturitional maternal rats given a choice between one of their own neonates who has received an experimental treatment vs. a litter mate control, prefer the control offspring. Exposing one half of a litter to either hypothermia treatment or mechanical rotation markedly affects one maternal behavior patternretrieval in the open field. The influence of the treatment was obvious in not only the maternal response to the treated neonates but also the untreated litter-mate controls. These results were most noticeable when the maternal Ss were given a double choice retrieval test. When Ss retrieved a single neonate the early disruption of retrieving was not maintained and the scores returned to pretreatment levels.

The results of this study are in agreement with Rosenblatt \& Lehrman's (1963) finding that maternal behavior is in part a function of the neonates stimulus value. The disruption of important maternal behavior patterns as a function of the treatment of the neonates suggests that much of the research reported on the influence of early experience may have a confounding variable. Although the treatment variable may have significant effects directly upon the neonate, it also influences maternal behavior. Denenberg \& Whimby (1963) have reported significant behavioral changes in later adult behavior as a function of the maternal behavior. Future research must independently assess the contribution of maternal response, neonatal reaction, and their interaction to experimental neonatal treatment.

\section{References}

Denenberg, V. H. The effects of early experience. In E. S. E. Hafez (Ed.), The behavior of domestic animals. London: Bailliere, Tindall \& Cox, 1962. Pp. 109-138.

Denenberg, V. H., \& Whimby, A. E. Behavior of adult rats is modified by the experiences their mothers had as infants. Science, $1962,142,1192-1193$

Levine, $\mathbf{S}$. The effects of infantile experience on adult behavior. In A. J. Bachrach (Ed.), Experimental foundations of clinical psychology. New York: Basic Books, 1962. Pp. 139-169.

Rosenblatt, J. S., \& Lehrman, D. S. Maternal behavior of the laboratory rat. In Harriet L. Rheingold (Ed.), Maternal behavior in mammals. New York: Wiley, 1963. Pp. 8-57.

\section{Note}

1. This research was supported by Public Health Service Grant MH 08543 from the National Institute of Mental Health. 